\title{
El Artista (1874-1875): una revista de transición
}

\author{
Marco Antonio Chavarín GonzÁlez*
}

\section{Resumen:}

Con este artículo ${ }^{1}$ se intenta explicar cómo un momento histórico resulta fundamental, tanto ética como estéticamente, en la configuración de una revista como El Artista. Bellas Artes, Literatura, Ciencias, publicación dirigida por Jorge Hammeken y Mexía y Juan M. Villela, entre 1874 y 1875 . Así, se refiere que el positivismo, apenas ocho años después de que Gabino Barreda lo instaurara como modelo educativo nacional a través de la Escuela Nacional Preparatoria, comenzaba a permear en los distintos ámbitos de la sociedad mexicana y que, como reacción a él, aparecían las primeras señales del modernismo literario en relación contradictoria con una forma utilitaria de ver la literatura; al menos, así lo dejan ver Hammeken y Rafael Martínez de la Torre en dos textos que señalan la belleza o la utilidad como premisa, respectivamente, de la misma manera que lo hicieron otros autores de generaciones distintas, todos con un discurso con algún que otro término heredado de las ciencias naturales.

\section{Palabras clave:}

Historia de la literatura, Publicación periódica, Literatura, Positivismo, Historia de la educación.

${ }^{1}$ Este artículo se realizó con apoyo del Fondo Nacional para la Cultura y las Artes a través del Programa de Fomento a Proyectos y Coinversiones Culturales 2015.

* El Colegio de San Luis. 
José Luis Martínez señala en La expresión nacional que El Artista. Bellas Artes, Literatura, Ciencias, nombre completo de la publicación, fue "una de nuestras más elegantes revistas literarias y en la que se advierten ya [“signos claros de desaparición” del romanticismo, así como] los primeros signos de las nuevas doctrinas literarias" (216). Esta publicación periódica -que estuvo dirigida por el escritor Jorge Hammeken y Mexía y el periodista Juan M. Villela, entre enero de 1874 y junio de 1875, y fue publicada a través de la imprenta de Díaz de León y White- logró, según lo expresa Octavio Gordillo Ortiz en "Catálogo de la revista El Artista", "una convivencia amistosa entre los escritores mexicanos de la talla intelectual de Flores, Acuña, Altamirano y Sierra" (Gordillo 64). Es decir, participó de esa tendencia hacia la concordia característica de toda una tradición de revistas mexicanas culturales misceláneas, en las que la literatura cumplía un papel esencial, tradición que inicia con El Año Nuevo. Presente Amistoso (1837), de Ignacio Rodríguez Galván, y es reiterada en El Renacimiento. Periódico Literario (1869), de Ignacio Manuel Altamirano y Gonzalo A. Esteva.

Aunque, incluso, antes de El Año Nuevo se tuvo una revista literaria como El Iris (1826), de José María Heredia y los italianos, Claudio Linati y Florencio Galli, considerada como la primer "revista literaria del México independiente" (Schneider xxv), El Año Nuevo fue la primera en ser fundada y dirigida por mexicanos. Además, en El Iris pronto se perdió la calidad literaria a favor del activismo político de sus fundadores, en especial de Linati y de Galli (Schneider lxiii). A pesar de que Gordillo Ortiz los presenta mezclados, pues por un tiempo pertenecieron al mismo grupo, Ignacio Manuel Altamirano (1834-1893) corresponde a la llamada por Fernando Tola de Habich generación del Liceo Hidalgo (Curiel 72; cuyo año decisivo es el 51, conformada por los nacidos entre el 21 y el 35), y Manuel M. Flores (1840-1885), Manuel Acuña (1849-1873) y Justo Sierra (1848-1912) a la de El Renacimiento (Curiel 72; cuyo año decisivo sería el 66, conformada por los nacidos entre el 35 y el 50), la que Altamirano denominó, en un primer momento, la generación de la República (Curiel 66). Esta segunda generación -llámese de El Renacimiento o de la República- se encuentra en un momento de tránsito hacia el modernismo. 
En este sentido, El Artista representa un caso particular en la historia de las revistas mexicanas que incluyeron literatura, pues, de acuerdo con el momento de la enunciación, la publicación periódica de Hammeken está situada también en una etapa de transición, al final de la República Restaurada (1867-1874) y en el preludio del Porfiriato, entre 1874 y 1875 . Y en un lugar poco claro, como parece sugerirlo José Luis Martínez, respecto de otras revistas literarias decimonónicas más estudiadas, como El Renacimiento, Revista Azul (1894) o Revista Moderna (1898) y, una intermedia, no tan estudiada, como Revista Nacional de Letras y Ciencias (1889). A diferencia de estas últimas, El Artista parece más bien una revista discreta, seria, poco protagonista, con un fin explícito, como El Año Nuevo o El Renacimiento, de democratizar el arte y la literatura y con otro implícito, más interesado en discutir, aunque de forma sencilla, asuntos literarios y artísticos, algunos de altos vuelos como en Revista Nacional de Letras y Ciencias, Revista Azul o Revista Moderna, que poco interesarían a las mayorías, como quizá pueda percibirse en algunos de los ensayos y/o artículos que se verán más abajo.

Respecto de la intención de los directores de El Artista y específicamente en lo que puede considerarse como la exposición del programa, en el artículo "El porvernir", de Rafael Martínez de la Torre -que en realidad es una carta dirigida a Hammeken, en la que más adelante se profundizará-, este último dice: "La esperanza de una patria feliz está cifrada en la universalidad de conocimientos difundiendo la enseñanza por todos los medios de que la sociedad puede disponer. El trabajo y la inteligencia son estériles sin el estímulo de la gloria o de la utilidad. Tales son los resortes poderosos que hacen a los hombres sabios pensadores filósofos, artistas [y...] el problema que debe resolver El Artista" (Martínez de la Torre 11). Hasta aquí parecería que el proyecto de esta revista solo implicaría una continuación de la función formadora propuesta por El Año Nuevo o El Renacimiento. Sin embargo, en el artículo introductorio "Ave Graecia!", de Hammeken, especie de oda a Grecia -sin afanes clasicistas- y a la cultura occidental, se da cuenta de que con El Artista no solo se busca enfatizar la función práctica de la literatura, sino también "levantar en este suelo un altar a la belleza" (Hamme- 
ken, Ave 4), premisas que, junto con la libertad en el arte y la búsqueda de asimilar obras de otras tradiciones literarias (Clark xiii-xiv), serían exaltadas por Gutiérrez Nájera en "El arte y el materialismo", publicado entre el 5 de agosto y el 6 de septiembre de 1876 en El Correo Germánico. Cabe recordar que este texto ha sido señalado por Clark de Lara y Zavala Díaz como el inicio del camino "en el anhelo por alcanzar la modernidad literaria" (Clark xiii) en México.

En el texto de Hammeken se puede encontrar, además, el regodeo en el estilo, similar al de los discursos oratorios de Jesús Urueta en Revista Azul y en Revista Moderna, o de los textos de carácter biográfico de Ciro B. Ceballos, compilados con algunos cambios en su libro En Turania. Retratos literarios (1902), también en la revista de Valenzuela, cuidando, por supuesto, el equilibrio con el contenido, pero sin preocuparse mucho por un lector poco culto. $\mathrm{Al}$ respecto, Luz América Viveros Anaya señala que el estilo de Ceballos “es, efectivamente, barroco, profuso en léxico poco usual, quizás equívoco para el lector novel, pero no para un crítico literario [...] Las ideas son claras pese a que el lenguaje, sobra decirlo, no es diáfano" (Viveros lviii). Asimismo, volviendo al texto de Hammeken, hay cierta "voluntad de idealismo" y de tendencia hacia la libertad ambos elementos del modernismo- como una respuesta en contra, quizá involuntaria en este caso, a la doctrina positivista, de la que el mismo Hammeken era estudioso y profundo conocedor:

El arte antiguo es el arte de la forma, el arte bizantino es el arte del espíritu. En el primero el hombre se sentía abrumado por la tierra, por la materia, por el fatalismo negro de un destino desconocido; el alma se hallaba detenida en esa trama grosera como ave prisionera en traidoras redes. Por eso falta expresión, movimiento, vida, alma a sus figuras y monumentos. En el segundo, el espíritu se ha separado ya de la prisión humana; libre e independiente se cierne en dilatados horizontes y escucha con místico arrobamiento las melodías sagradas que se desprenden de las angélicas arpas (Hammeken, Ave 6).

De esta manera, no es de extrañar que se detecte un positivismo diluido con lo que quedaba de los afanes democratizadores de 
la euforia nacionalista de la República Restaurada, así como una inquietud intelectual y artística que ya no era del todo romántica ni nacionalista ni tampoco dejaba de serlo, una especie de amalgama contradictoria con algunos elementos que después serían parte de lo que se conocería como modernismo; combinación, sin embargo, capaz, desde mi perspectiva, de permitir un sano equilibro entre los niveles ético y estético de los diversos textos que se escribieron para la revista o se eligieron para ella traídos de otros espacios. Como también lo refieren Clark de Lara y Zavala Díaz, en México:

la entrada a la modernidad la encontramos primero en el campo de las ideas hacia 1867-1868, cuando Gabino Barreda adaptó el positivismo comtiano al medio mexicano. En economía, aunque ya durante la República Restaurada (18671876) se habían dado los primeros intentos por propiciar el desarrollo del país, en realidad, el proceso modernizador arrancó en 1877 con el programa de Paz, Orden y Progreso de Porfirio Díaz, que se afirmó, de manera clara, durante el cuatrienio de Manuel González (1880-1884). En el campo de las letras las primeras manifestaciones 'modernas' aparecieron entre 1875 y 1876 en la prosa de José Martí y Manuel Gutiérrez Nájera (Clark x).

Señalamiento, este último -recuérdese que El Artista principia en 1874-, que permite pensar en la revista de Hammeken como una de las plataformas en la que se ensayarían esas "nuevas doctrinas" que refiere Martínez. De ahí que, además de los escritores señalados, participarían en la revista escritores mexicanos como Gustavo Baz, Pedro Castera, José Tomás de Cuéllar, Manuel Acuña, Manuel M. Flores, Eduardo A, Gibbon, Luis Lasso de la Vega, Vicente E. Manero, Manuel de Olaguíbel, Manuel Orozco y Berra, Manuel Peredo, Francisco Pimentel, Ramón Rodríguez Rivera, Eduardo Ruiz, Gaspar Sánchez Ochoa, Ramón Valle y Julio Zárate.

Entre los escritores extranjeros están los novelistas Víctor Hugo, Lucién Biart y Edward Jenkins, como un abanico de posibilidades, 
romanticismo, costumbrismo y realismo o naturalismo, respectivamente. Juan M. Villela traduce y publica una de las novelas cortas de Biart, Lo que puede la mujer y hace un análisis de este texto y otros más en el ensayo "Mr. Lucién Biart. Costumbres mexicanas. I". Entre los elementos que Villela enfatiza de la obra del francés están la construcción de un México de provincia sin prejuicios eurocentristas ni centralistas - pues las acciones se desenvuelven en territorio del estado de Veracruz, descrito cuidadosamente y sin menosprecio-, así como el uso de personajes femeninos idealizados. Algunos de los señalamientos de Villela concuerdan con los de Altamirano en Revistas Literarias de México (1868), cuando habla de la novelística de Florencio M. del Castillo, y admira la belleza de tipos, el estudio de caracteres, la ternura de los amores presentados, el estilo elegante y el fluido diálogo, la verdad de las descripciones; es decir, cuando describe, prácticamente, a Clemencia (1869) como ejemplo de cómo y por qué él creía que debería de escribirse novela en México. Así, respecto de la configuración de los personajes femeninos, se puede leer que Altamirano señala de la narrativa de Castillo que sus heroínas

son jóvenes virtuosas, apasionadas, melancólicas con esa melancolía que hace llorar y no aborrecer al mundo, con esa melancolía que da dulzura al alma de la mujer, como la blanda luz de la luna da un color suave a su semblante. Ellas aman y sufren, y luchan y lloran en silencio; pero jamás se desesperan, jamás se sublevan contra el destino, jamás sucumben vergonzosamente, jamás se hunden en la perdición. En esas vírgenes pálidas y enamoradas cree uno ver ángeles, y se adivinan tras de ellas las alas de la inocencia plegadas por la resignación y el dolor, pero dispuestas a abrirse para remontar al cielo" (63).

De manera muy parecida, Villela dice que:

En general, los caracteres [femeninos] que presenta Mr. Lucien Biart, son verdaderos tipos sociales, tan reales como numerosos. Todos son consecuentes, verídicos y naturales. En 
él hay una tendencia a hacer amar y compadecer a la mujer; no por eso pretende su emancipación política: quiere únicamente que sea amada y respetada. Las otras figuras que presenta están muy estudiadas y cada una de por sí es un modelo digno de ser imitado. Defectos se encuentran, pero las bellezas abundan" (26).

Manuel de Olaguíbel publica también un pequeño relato titulado en alemán "Wein, Weib und Gesang", que puede ser traducido como "Vino, mujeres y música", en el que se percibe un espacio-tiempo configurado -como lo harán los modernistas- mediante tapices de Persia, libreros de nogal y libros ricamente encuadernados, cómodas y escritorios de Boulle y de mosaico de madera rodeadas de estatuas de mármol y bronce, así como -según lo exhibirían los decadentistas- el gusto por el vino y las mujeres en un ambiente que intenta ser bohemio. La historia trata de una reunión de artistas que tiene lugar en una lujosa biblioteca de la casa de Juan, el amigo del narrador. En esta tertulia los personajes son instados a hablar sobre varios temas: la mujer, el vino -sobre cuyo efecto intentan reflexionar el narrador y su amigo-, el Diablo, y algunos escriben algún poema, tocan o improvisan una melodía en el piano o hacen algún retrato de los asistentes. Hay incluso alusiones a la vida disipada de algunos invitados con comentarios como "no veo qué tenga esto de común con una orgía” (Olaguíbel 12).

Cabe señalar que el texto del padre de Francisco Modesto se construye -principalmente sobre la base de un espacio hasta cierto punto detallado- a partir de los fragmentos del diálogo de cinco personajes a los que no se termina de configurar, pues parece, como en el impresionismo, querer mostrarse un todo mediante unas cuantas pinceladas que combinan la voz del narrador con el diálogo directo de los personajes:

Juan abrió la sesión con estas palabras [...] El músico se acercó al piano y comenzó a improvisar algo enteramente fantástico [...] Juan sacó de la cómoda dos botellas de Markobrüner y seis de esas graciosas copas verdes con bases de cristal cuajado [...] el primero de los dos poetas se levantó, preten- 
dió arreglar su negra melena, y tomando un volumen tradujo y dio lectura al siguiente pasaje [...] Inmediatamente después tocó el joven músico la ‘danza osiánica’ de Gotschalk [...] El pintor que había permanecido en el otro extremo de la sala, se acercó con un papel en la mano (Olaguíbel 12-15).

Como se observa, solo cito y rápidamente los señalamientos del narrador con el fin de enfatizarlos más; sin embargo, cada una de estas entradas va acompañada por lo que dice algún personaje como: "He mandado invitar a ustedes porque no es fácil que nos reunamos frecuentemente", cuando Juan les da la bienvenida, o bien: "¿Qué idea te has formado [...] de los efectos que produce el vino?” (Olaguíbel 13), cuando Juan abre la botella de Markobrüner. De cualquier manera, debido a que el texto es poco extenso, la sensación de acumulación de imágenes, como en rápidas pinceladas, se revela como el principio constructivo del texto.

Como ya se ha referido, en El Artista no hay un texto introductorio que dé cuenta del programa de la revista, pero sí el ensayo, ya mencionado, de Martínez de la Torre que da cuenta de la función que la revista debía cumplir en su momento a partir de la siguiente idea: "El trabajo y la inteligencia son estériles sin el estímulo de la gloria o de la utilidad. Tales son los resortes poderosos que hacen a los hombres sabios, pensadores, filósofos, artistas" (Martínez de la Torre 11). Postura que, al igual que en novelas como Ensalada de pollos (1869), de José Tomás de Cuéllar, o La Calandria (1889), de Rafael Delgado, idealizaría el trabajo constante como mecanismo real de ascenso social.

Martínez de la Torre aboga por una educación universal no aristocrática, basada en la consagración del trabajo, poniendo especial atención en los indígenas, porque "Educar a estas razas es el primero de los deberes entre nosotros" (Martínez de la Torre 12); también habla a favor de la promulgación del español como lengua base para toda la República. De ahí que, como Altamirano, proponga el uso de un estilo sencillo basado en la premisa de lo útil y lo bello, pues advierte que no se debe olvidar "que hay muchos entre ese mismo pueblo, desheredados de instrucción, viviendo bajo un 
cielo espléndido y atravesando en su carrera sobre la tierra un suelo que a su paso solo les ofrece ignorancia, pobreza, esterilidad y sufrimiento" (Martínez de la Torre 12).

Estas últimas palabras recuerdan las de Altamirano en la ya mencionada Revistas Literarias de México, cuando recomienda el uso de la novela como mecanismo de instrucción y de propaganda (Altamirano 80); al respecto y en cuanto a la función instructiva, señala:

nosotros hemos considerado la novela como lectura del pueblo, y hemos juzgado su importancia [...] por la influencia que ha tenido y tendrá todavía en la educación de las masas. La novela es el libro de las masas. Los demás estudios, desnudos del atavío de la imaginación, y mejores por eso, sin disputa, están reservados a un círculo más inteligente y más dichoso, porque no tiene necesidad de fábulas y de poesía para sacar de ellos el provecho que desea [...] El hecho es que la novela instruye y deleita a ese pobre pueblo que no tiene bibliotecas, y que aun teniéndolas no poseería su clave (Altamirano 57).

En este sentido es que Martínez de la Torre concluye que El Artista

debe ser el libro que despierte los grandes pensamientos, los sueños de poesía, el amor a lo grande, la admiración de lo maravilloso; pero entre ese coro de amor a la gloria, entre ese cántico al progreso, debe haber una voz que repita que para recorrer la escala del genio se comienza por la escuela: que ella es la única esperanza para que entre las agonías de la existencia anémica del pueblo ignorante se vea una luz que, pequeña en su origen, pueda ser el gran luminar del porvenir de México (Martínez de la Torre 14).

No está de más señalar que inclusive a pesar de las diferencias ideológicas entre Altamirano y Martínez de la Torre, ambos coinciden en que la literatura puede ser usada para instruir y formar al pueblo. Lo anterior, aunque Martínez de la Torre era conocido como conservador y uno de los abogados que defendió, junto 
con Mariano Riva Palacio, a Maximiliano de Habsburgo en el juicio donde fue ejecutado junto con los generales mexicanos conservadores Miramón y Mejía.

Esta etapa de transición del nacionalismo característico del segundo romanticismo mexicano -el de la República Restaurada- a algo más, también es perceptible en dos momentos del texto de Martínez de la Torre: primero, cuando se propone una idea de artista, para cuya formación "se necesita que la idea y el sentimiento, el placer y el dolor tengan su inspiración en la fuente inagotable del corazón humano, en la revelación omnipotente de la ciencia, en la luz infinita de la civilización" (Martínez de la Torre 13), idea que trata de encontrar un equilibrio entre sentimiento y razón.

El segundo momento es cuando poniendo énfasis en lo bello, Martínez de la Torre comenta que para entender a los autores de ese tiempo debían existir receptores con posesión del "instinto de la poesía universal y el sentimiento de ese goce infinito que estremece el corazón y humedece los ojos en la contemplación de lo bello, de lo extraordinario, de lo maravilloso" (Martínez de la Torre 13); es decir, la revista debería ayudar en la formación de receptores de arte y literatura para que pudieran percibir algunos elementos como la belleza. Así, la publicación periódica sería no solo una plataforma para ensayar "nuevas doctrinas" sino también para formar "nuevos lectores" y espectadores.

Por lo anterior, llama la atención la presencia del texto "La literatura nacional", ensayo que, como se recordará, José Tomás de Cuéllar publicó primero en La Ilustración Potosina (1869) y luego en El Renacimiento en 1869. Sobresale, principalmente, porque en lugar de que Hammeken y Villela hayan acudido a algún texto previo de Altamirano, quien colaboró en El Artista con un discurso y dos artículos, o solicitado un texto nuevo que diera cuenta de lo que se debería entender por literatura, se transcribe un texto publicado por primera vez en San Luis Potosí, de un escritor ya entonces bastante conocido y quien siempre se sintió muy atraído por el positivismo, pero que no era el padre de las literatura nacional; es decir, no era Altamirano, el maestro de Hammeken. 
La estrecha relación entre la literatura y el medio, con la que Cuéllar inicia su texto y que Hammeken, citando a Hyppolyte Taine y la idea de la "temperatura moral", también utiliza en "El arte y el siglo" - ensayo que más adelante se abordará-, debió de ser una motivación afín con la idea de una literatura útil que buscada esta publicación periódica:

La literatura [dice el escritor de Ensalada de Pollos] es la expresión del estado de la civilización de un pueblo [...] y esta verdad se pone de manifiesto en la historia de la literatura de México. La literatura es, no sólo el termómetro de la civilización, sino el reflejo de la historia de los pueblos. Es como la voz inmortal de las grandes catástrofes y de las transformaciones seculares, es el acento expresivo de los sacudimientos y de las revoluciones, que resuena desde los siglos más remotos hasta la más remota posteridad (Cuéllar 209).

En otras palabras, según esta propuesta, la literatura no solo expresa el progreso de un país, sino también es la evidencia de una serie de momentos específicos de la historia de ese país. Utilidad nada despreciable que, por lo regular, se pierde de vista. En ambos casos, sin embargo, se da cuenta del aspecto práctico, ya sea en el corto o mediano plazos, para el caso que se requiera referir el progreso de una nación, y otra, en el mediano o largo plazos, cuando se necesiten reconocer las características de una sociedad en el futuro. Ya sea para un político, un historiador o un crítico literario, la utilidad sería innegable.

Esta insistencia casi obsesiva en la utilidad de la literatura se justifica cuando Cuéllar señala - una idea nada ajena al siglo XXI- que en el siglo XVIII la literatura era considerada por algunos

como un juego de ingenio, como un pasatiempo despreciable y de ninguna utilidad. No se concebía al poeta sino como al hombre que sabe hacer reír, como al saltimbanqui que sabe hacer suertes; de manera que era ajeno de toda gravedad e incompatible hasta con la posición social, entretenerse en cosas de literatura, bagatelas propias de estudiantes y de ingenios 
frívolos [idea que incluso llegó hasta la tercera década del XIX, donde...] el poeta era considerado como un ente extraño y ridículo, sobre el que caía el escarnio de lo que en México se llamaba nobleza y aristocracia. El carácter distintivo que los aventureros enriquecidos dieron a nuestra sociedad era el de una riqueza ostentosa y de mal gusto: riqueza oligárquica, cuyos blasones eran la vajilla de plata maciza; y el nombre de poeta sonaba como sinónimo de pobre y necio en aquellos altos círculos (210-211).

Al igual que Altamirano, Cuéllar establece un nexo entre la literatura mexicana en 1869 y la de la Academia de Letrán y el Liceo Hidalgo, considera la época del Segundo Imperio como infértil, literariamente hablando, y asegura que la restauración de la República fue el "renacimiento de las letras, abriendo una nueva era de verdadero progreso intelectual, y por la primera vez en la República se nota el sorprendente movimiento literario que agita hoy a todos los hombres de letras [...] la primera época verdaderamente floreciente de las letras en México [y termina, casi con una plegaria, con el fin de que...] esta fuente de vida y prosperidad de la patria" (Cuéllar 213) no fuera interrumpida por alguna otra guerra civil. Deseo que, como sabemos, no se cumplió.

Donde se vislumbra más claramente esa especie de transición que he ido señalando a lo largo de este artículo, es en el ensayo, ya mencionado, "El arte y el siglo", de Hammeken. El texto es antecedido por una dedicatoria: "A mi maestro Ignacio M. Altamirano" e inicia con una cita en francés del filósofo Robert de Lamennais, aunque con la traducción a pie de página; transcribo esta última: "El viejo mundo [dice Hammeken] se disuelve, las antiguas doctrinas, desaparecen; pero en medio de un trabajo confuso, de un desorden aparente, alborean ya las nuevas doctrinas, organízase un nuevo mundo; la religión del porvenir proyecta sus primeros resplandores sobre el género humano que espera y sobre sus destinos el artista debe ser el profeta de esta religión" (El arte 133).

Como se observa, además de enfatizar la influencia francesa en la lengua y en el pensamiento, aunque sin descuidar a los que no 
saben francés, el crítico no solo delimita una nueva forma de ver el mundo respecto de una vieja, sino que también refrenda una misión para el escritor, especie de apóstol del porvenir, que deberá guiar al resto de los humanos por el camino del progreso. Esa misión que Jorge Ruedas de la Serna señala que si bien "fue un obstáculo para la imaginación creadora o resultó perjudicial al vuelo de la fantasía o la audacia poética, que son al final signos de madurez en una literatura [..., favoreció en cambio la expresión de un contenido humano, bien significativo de los estados de espíritu de una sociedad que se estructuraba sobre bases modernas (9-10).

Más adelante, Hammeken, como para dar un ejemplo a seguir, señala la evolución que sufrió Lamennais de "máquina muda en ser pensador, de la conciencia esclava a la conciencia libre" (El arte 133), aboga por la libertad de pensamiento y las nuevas formas de concebir el mundo, poniendo especial énfasis en lo nuevo, lo moderno: "Religión nueva, mundo nuevo, civilización nueva, y arte también nuevo" (El arte 133). Con esto, Hammeken da cuenta, sobre todo, de la armonía que existe o que puede existir entre literatura y arte con la modernidad:

Porque parece, a primera vista, que entre este mundo filisteo que venera a un Offenbach y denigra a un Goëthe, que sueña con ferrocarriles y desprecia la cultura intelectual, que se nutre con las máximas de un Comte e ignora que existe un Carlyle, que tiene la mirada fija en el Vaticano y anatematiza a Rénan, a Víctor Hugo y a Flammarion, que se llama Comuna en la política, Émile de Girardin en la prensa, Monsieur, Madame et Bébé en la literatura, Courbet y la escuela ultra-realista en el arte, Meilhac y Halevy en el teatro, Mac-Mahon y Serrano en el poder, el adulterio en el matrimonio, la corrupción en las costumbres, el dinero y el favoritismo en la aristocracia, el rococó y la extravagancia en el gusto, la frivolidad y el champagne en la cabeza, la depravación y el libertinaje en la conducta, y ese otro mundo sereno y apacible, poético y sublime del Arte, no hay no puede haber contacto alguno, ni simpatía alguna, ni atracción mutua. 
Y, sin embargo, hay contacto, existe la simpatía, obra la atracción entre esos mundos en apariencia tan diversos ("El arte" 134).

Según se ve, la idea del arte se construye aquí, como en el caso de "¡Ave Graecia!" arriba señalado, con base en una acumulación de imágenes, mediante oraciones coordinadas y subordinadas, que recuerdan, como también ya se dijo, el estilo de Jesús Urueta en Revista Azul y en la primera etapa de Revista Moderna, y donde se sugiere que el arte debe nutrirse de su medio, de su momento histórico, porque un "siglo como éste debe tener su arte propio, individual, que penetre de su espíritu y de su alma" ("El arte" 134). Hammeken justifica esta idea en una cita de Taine, una vez más en francés con su traducción en nota al pie:

De la misma manera que existe una temperatura física que, por sus variaciones, determina la aparición de cierta especie de plantas, existe, también, una temperatura moral que, por sus variaciones, determinan la aparición de cierta especie de arte. Y de la misma manera que se estudia la temperatura física para comprender la aparición de cierta especie de plantas, el maíz o la avena, el aloe o el abeto, así también es necesario estudiar la temperatura moral para comprender la aparición de cierta especie de arte, la escultura pagana o la pintura realista, la arquitectura mística o la literatura clásica, la música voluptuosa o la poesía idealista. Las producciones del espíritu humano como las de la naturaleza viviente, sólo se explican por el medio que las rodea ("El arte" 135).

Este interés por Taine no solo revela su influencia -por aquello de la raza, el medio y las circunstancias- sino también el presagio de una nueva forma de acercamiento al arte y a la literatura en México, la decadentista, que surge, como Jesús E. Valenzuela lo reconoce en dos textos que publicó con el título de "Los modernistas mexicanos" -ambos publicados originalmente en El Universal, el 26 de enero y el 4 de marzo de 1898, respectivamente, y después en Revista Moderna, la primera y la segunda quincenas de diciembre de 1898, respectivamente-, donde habla del pesimismo, resultado de la 
pérdida de la fe en Dios y de la imposibilidad de obtener todas las respuestas mediante el método científico; todo como resultado de la educación positivista que habían recibido los mexicanos:

Y conste que no he dicho que Urueta, Tablada y Dávalos fueron discípulos directos de Barreda, cuando ellos llegaron -son menos viejos que yo- ya se había volcado la nueva enseñanza de la cátedra de don Gabino en la Escuela y de ésta en las plazas públicas. Se tragaba con el polvo de las calles. Hoy hasta los estadistas católicos siguen el método científico $[\ldots]$ porque es un método para investigar, dice usted [Salado Álvarez]; exactamente; pero detrás del método está el hecho, dice Bourget, y ya ve usted a qué largas consecuencias arrastra el estudio de los hechos: el pesimismo, el nihilismo, el nirvana, según el crítico francés, porque la ciencia no puede llegar hasta ahora al fondo íntimo, inmortalmente nostálgico del corazón (Valenzuela 156).

De ahí, de una doctrina que despojaba de respuestas y que era incapaz de contestar a todas las preguntas, de ahí surge, según Clark de Lara y Zavala Díaz, esa voluntad de idealismo que "llevó a enarbolar los estandartes de la belleza, del constante cambio y de la redención social, para suplir la ausencia de Dios" (Clark xvi). Ya Gutiérrez Nájera señalaría las afectaciones del positivismo sobre el arte en "El arte y el materialismo", en 1876, dos años después del texto de Hammeken y 22 antes del texto de Valenzuela, cuando discutiendo con Pantaleón Tovar, aboga por la libertad del arte en contra de las limitaciones de la escuela realista:

Lo que nosotros combatimos y combatiremos siempre, es esa materialización del arte, ese asqueroso y repugnante positivismo que en mal hora pretende introducir en la poesía; ese cartabón ridículo a que se pretende someter a todos los poetas, privándoles así de la libertad; cartabón que excluye como inútiles o maléficos a todos los géneros sentimentales, y que sólo acepta al mal llamado género realista (Gutiérrez, "El arte" 12). 
Al respecto, Hammeken comenta que "Nuestro arte moderno, el arte del siglo xIx, debe ser realista en la forma, espiritualista, idealista, liberal, progresivo en el fondo." (El arte 136). Es decir, aunque se opta por una presentación realista, cuando se refiere al contenido se advierte de un arte en constante cambio, como lo entenderá Gutiérrez Nájera en "Al pie de la escalera", la introducción al primer número de Revista Azul, con todos esos elementos que al final terminarán por romper los cimientos realistas y esas tendencias positivistas, mediante el espiritualismo o el idealismo: "Nuestro programa se reduce a no tener ninguno [...] Hoy, como hoy; mañana de otro modo; y siempre de manera diferente" (Gutiérrez, "Al pie” 2). Aun así, en Hammeken hay un énfasis en la función de la literatura, en ese apostolado que se convierte en misión:

El arte para el arte, el arte que no tiene más objeto que la adoración de la belleza o la satisfacción de los sentidos, que se convierte en sacerdote de la religión o en apóstol de la inmoralidad, que se emancipa del fin a que tiende toda nuestra civilización y toda nuestra energía [...] es un arte falso, absurdo ilógico, improductivo, nocivo, que debe ofrecer sus altares y sus discípulos, sus templos y sus apóstoles a la nueva religión que proclama la elevada misión, el sacerdocio sagrado, el ideal divino del arte democrático ("El arte" 136).

Casi al cierre, Hammeken, poniendo énfasis en el movimiento, la belleza, la libertad y en la misión de escritor, señala:

Bastante tiempo ha tenido el Arte los brazos cruzados. Tiempo es ya de moverse, de entrar un poco en ejercicio, de cooperar en la grande obra, de ayudarnos en la colosal empresa, de descender de las galería de los lores, de las cocottes, de los claustros y de las academias, para mezclarse en nuestra vida y sufrir con nuestros sufrimientos, para alentarnos en la desgracia y subir a la trípode de la pitonisa, traduciéndonos el estremecimiento del follaje, los murmurios del sagrado bosque, los mandatos del divino oráculo, y las promesas de la nueva vida; tiempo es ya de recordar las hazañas de nues- 
tros héroes, las lágrimas de nuestras vírgenes, las caricias de nuestras madres, las bellezas de nuestros campos; tiempo es ya de arrojar el guante a esta sociedad corrompida y filistea, de avergonzarla y vencerla con los cuadros del hogar, de la familia, de la libertad y de la patria; tiempo es ya de tocar la campana de alarma para agrupar a los amigos del progreso alrededor de una bandera que proclama el odio al fanatismo y el amor a la libertad, la execración de la mentira y el apego a la verdad, la muerte del mundo antiguo y el nacimiento del mundo nuevo ("El arte” 136-137).

Larga pero necesaria cita en la que se percibe una combinación contradictoria pero funcional; a través de ella se entiende la visión que se privilegiará en la revista sobre el arte y la literatura y, por tanto, sobre el artista, justo en medio de una visión todavía nacionalista - "la libertad y la patria"- de la que no pueden escapar y con la esperanza de entrar de lleno en la modernidad -el "progreso" y el "mundo nuevo"-. En resumen, el positivismo y el modernismo son dos de esas "nuevas doctrinas", señaladas al inicio, que alcanzan a percibirse en ciernes en esa revista de transición que es El Artista y que en años posteriores, primero, con Revista Nacional de Artes y Ciencias y, después, con Revista Azul y Revista Moderna terminarán por mostrarse completamente e integrarse a la tradición literaria y artística.

Si bien, en El Artista la tendencia romántica sigue presente, la costumbrista, la realista y la naturalista están fuertes, el mismo eclecticismo característico de nuestros escritores desde inicios del siglo xix permitió que algunos elementos de las nuevas tendencias comenzaran a hacerse presentes sin muchos aspavientos, en la sobriedad elegante que, según José Luis Martínez, caracterizó a esta revista y que, a mi ver, permitió un buen equilibrio entre la misión exigida al escritor decimonónico por el nacionalismo dogmático y la búsqueda, quizá todavía no del todo consciente, de una literatura propia.

Esto último, según la idea que Gutiérrez Nájera manejaba sobre "El cruzamiento en la literatura" -texto publicado primeramente 
en El Partido Liberal en 1890, donde se proclamaba la necesidad de que las literaturas extranjeras permearan en las nacionales- y que implicaba la asimilación de otras culturas literarias: "Conserve cada raza su carácter substancial; pero no se aísle de las otras ni las rechace, so pena de agotarse y morir" (Gutiérrez, El cruzamiento 93). Afirmación que se siente, al menos, extraña en boca de este escritor decimonónico; sin embargo, a la vez, revela que, incluso a pesar del rechazo consciente del positivismo, la doctrina comenzaba a ser asimilada por todos -asimilación que en México, según Leopoldo Zea (69), dejó siempre del lado la idea de libertad y solo asumió el orden y progreso-. Particularidad que daría la razón a Jesús E. Valenzuela, quien, como se vio, justificaba el nacimiento del decadentismo a través de la imposición del positivismo por Gabino Barreda, asegurando que, en México, a finales del siglo xix, "Se tragaba con el polvo de las calles". Al final, como al parecer sucedió, los argumentos antidecadentistas de Victoriano Salado Álvarez, el más fuerte e instruido enemigo, habrían sido derrotados por los hechos históricos que le dieron, sin duda alguna, la razón a Valenzuela y al grupo que se formaría en torno de Revista Moderna, en cuyas páginas se llega a la cúspide de algunas de las ideas sembradas más de dos décadas atrás en la revista El Artista, por lo que puede considerársele, si bien lejana, una digna precursora.

\section{Obras citadas}

Altamirano, Ignacio Manuel. "Revistas literarias de México. (18211867)". Obras Completas. Ignacio Manuel Altamirano. xii. Escritos de literatura y arte, tomo 1, selección, prólogo y notas de José Luis Martínez. CONACULTA / Tribunal Superior de Justicia del Distrito Federal, 2011, pp. 29-178.

Viveros Anaya, Luz América. "Estudio Preliminar. Retratos literarios para una galería del modernismo mexicano", en Ciro B Ceballos. En Turania. Retratos literarios (1902), edición crítica, notas e índices de Luz América Viveros Anaya. UNAM, 2010, pp. xi-lxxiv. 
Cuéllar, José Tomás de. "La literatura nacional". El Artista. Revista Mensual de Bellas Artes y Literatura, tomo iii, 1875, pp. 209-213.

Clak de Lara, Belem y Zavala Díaz, Ana Laura. "El modernismo a través de sus polémicas". La construcción del modernismo (Antología), introducción y rescate Belem Clark de Lara y Ana Laura Zavala Díaz. UNAM, 2002, pp. ix-xliii.

Curiel Defossé, Fernando. Elementos para un esquema generacional aplicable a cien años (aprox.) de literatura patria. UNAM, 2001.

Gutiérrez Nájera, Manuel. "Al pie de la escalera”. Revista Azul, tomo I, núm. 1, 1894, pp. 1-2.

Gutiérrez Nájera, Manuel. "El arte y el materialismo". Clark y Zavala, pp. 3-32.

Hammeken y Mexía, Jorge. "Ave Graecia!”. El Artista. Revista Mensual de Bellas Artes y Literatura, tomo i, 1874, pp. 3-7.

---. "El arte y el siglo". El Artista. Revista Mensual de Bellas Artes y Literatura, tomo i, 1874, pp. 133-138.

Martínez, José Luis. La expresión nacional. Editorial Oasis, 1984.

Martínez de la Torre, Rafael. "El Porvenir". El Artista. Revista Mensual de Bellas Artes y Literatura, tomo i, 1874, pp. 11-14.

Olaguíbel, Manuel. "Wein, Weib und Gesang". El Artista. Revista Mensual de Bellas Artes y Literatura, tomo ii, 1874, pp. 11-16.

Ruedas de la Serna, Jorge. "Presentación". La misión del escritor. Ensayos mexicanos del siglo xix, organización de Jorge Ruedas de la Serna. UNAM, pp. 7-13.

Schneider, Luis Mario. "La primera revista literaria del México independiente". El Iris. Periódico Crítico y Literario, por Linati, Galli y Heredia, tomo I, edición facsimilar e introducción de María del Carmen Ruiz Castañeda. UNAM, pp. xxv-lxiii.

Valenzuela, Jesús E. "Los modernistas mexicanos". Revista Moderna. Literaria y Artística, tomo 1, núm. 10, 1898, pp. 152-157.

Villela, Juan M. "Mr. Lucien Biart”. El Artista. Revista Mensual de Bellas Artes y Literatura, tomo I, 1874, pp. 19-27

Zea, Leopoldo. Elpostitivismo en México: Nacimiento, apogeo y decadencia, Fondo de Cultura Económica, 2005. 